\title{
A self-powered gas sensor based on PDMS/Ppy triboelectric-gas-sensing arrays for the real-time monitoring of automotive exhaust gas at room temperature
}

\author{
Haoxuan $\mathrm{He}^{1,2}$, Mengyang Zhang ${ }^{2}$, Tianming Zhao ${ }^{1,2}$, Hui Zeng ${ }^{2}$, Lili Xing ${ }^{1,2^{*}}$ and Xinyu Xue ${ }^{1,2^{*}}$
}

\begin{abstract}
A new self-powered active gas sensor for realtime monitoring of automotive exhaust gas was devised. The pipe-shaped device was fabricated from polydimethylsiloxane/ polypyrrole (PDMS/Ppy) triboelectric gas-sensing unit arrays. The gas-sensing units can actively convert the mechanical energy of gas flow into a triboelectric current. The output current signal depends on the species and concentrations of the target chemical gases $\left(\mathrm{CO}, \mathrm{NH}_{3}, \mathrm{NO}\right)$ in the gas flow, and thus can be used as a sensing signal. The device consists of seven gas-sensing units with different Ppy derivatives. As the different sensing units respond to the gases in different ways, the device can differentiate between gas species. The working mechanism is attributed to the coupling effect between the triboelectric effect of PDMS/Ppy and the gas-sensing properties of Ppy. The device can be installed in the tailpipe of an automobile, and can thus analyze the exhaust gas in real time without the need for any external electrical power. The results of the present study spur a new research direction for the development of automotive exhaust gas monitoring systems, thus playing an important role in the detection of air pollution.
\end{abstract}

Keywords: self-powered, gas sensing, triboelectrification, automotive exhaust gas, coupling effect

\section{INTRODUCTION}

In modern society, automobiles are an essential means of transportation [1-3]. There are about half a billion automobiles on the roads every day. This makes people's lives more convenient but also generates large amounts of pollutant gases, such as carbon monoxide (CO), nitric oxide (NO), ammonia $\left(\mathrm{NH}_{3}\right)$, and volatile organic com- pounds (VOCs) [4-12]. None of $\mathrm{NH}_{3}, \mathrm{CO}$, or $\mathrm{NO}$ can be detected by the human senses. It is very important to have a means of selectively and rapidly detecting automotive exhaust gas in the atmosphere [13-15]. However, traditional automotive exhaust gas sensors incur problems associated with their large size, while their bulky integrated power units prevent real-time monitoring [16$24]$. The power supply unit embedded in a gas sensor has become a bottleneck to the application of conventional sensors [25-27]. If the power supply unit is large enough to provide sufficient energy, the sensor will likely be big and heavy. On the other hand, a small power supply unit would have a minimal capacity and thus would have to be frequently recharged, such that the collection of vital data would be missed. Moreover, the maintenance costs associated with the power supply units would increase with the usage of the sensors [28]. Therefore, a self-sustainable small gas sensor, which could be easily installed in an automobile with no need of an external power source, would be a major contribution to the development of intelligent vehicles.

Recently, self-powered gas-sensing systems have been developed by integrating gas sensors and triboelectric nanogenerators to solve the problem of providing the sensor with a reliable power supply [29-33]. Moreover, in our previous work, triboelectrification and gas-sensing processes were combined into a single device (a selfpowered active gas sensor). The triboelectric output of the device under applied mechanical deformation was dependent on the gas atmosphere [34,35]. The output triboelectric signal can act as both the power for driving the device and the gas-sensing signal [36,37]. This self-pow-

\footnotetext{
${ }^{1}$ School of Physics, University of Electronic Science and Technology of China, Chengdu 610054, China

${ }^{2}$ College of Sciences, Northeastern University, Shenyang 110819, China

* Corresponding authors (emails: xinglili@mail.neu.edu.cn (Xing L); xuexinyu@mail.neu.edu.cn (Xue X))
} 
ered active gas sensor is very suitable for the real-time monitoring of automotive exhaust gas, but requires the development of a new materials system and device structure. Given the wide variety of automobile tailpipe shapes, a flexible pipe-shaped device with gas-sensing arrays would be a good configuration. Various polypyrrole (Ppy) derivatives with different chemical/physical properties and charge characteristics can be easily modified by using different dopants and surfactants in the synthetic process, which can be selected to realize the monitoring of different gases in multiplexed sensing arrays [38-42].

In the present study, a new type of self-powered gas sensor for the real-time monitoring of automotive exhaust gases was developed. Based on the triboelectric/ gas-sensing coupling effect, polydimethylsiloxane/Ppy (PDMS/Ppy)-nanostructure gas-sensing arrays are realized as a pipe-shaped device. Driven by the gas flow, the sensing unit arrays can output a series of triboelectric current signals dependent on the gas species and concentration in the gas flow. When installed in an automobile tailpipe, the device can monitor and calibrate the exhaust gas in real-time without any external electrical power source. This new self-powered gas sensor could be applied to future intelligent vehicles.

\section{EXPERIMENTAL}

\section{Fabrication of self-powered gas sensor}

The fabrication of self-powered gas sensor started with the creation of a pattern on copper foil using a photolithography method. The $\mathrm{Cu}$ foil was cleaned using deionized water and ethanol for several times. Then, $3 \mathrm{~mL}$ of positive photoresist was spin-coated onto the $\mathrm{Cu}$ foil at $200 \mathrm{rpm}$ for $15 \mathrm{~s}$, and then at $1500 \mathrm{rpm}$ for $40 \mathrm{~s}$. Then, the $\mathrm{Cu}$ foil was dried at $100^{\circ} \mathrm{C}$ for $150 \mathrm{~s}$ and fixed in a photolithography machine by being exposed to UV light for $2.4 \mathrm{~s}$, thus producing the desired pattern. After that, the prepared $\mathrm{Cu}$ foil was immersed in developer for $60 \mathrm{~s}$, and then washed with deionized water and dried in $\mathrm{N}_{2}$ flow. Then, the prepared $\mathrm{Cu}$ foil was hardened at $120^{\circ} \mathrm{C}$ for $150 \mathrm{~s}$. The photolithography process was performed in the dark. Next, the $\mathrm{Cu}$ foil with the photoresist pattern was wet-etched by being soaked in etching liquid $\left(0.5 \mathrm{~mol} \mathrm{~L}^{-1}\right.$ sodium persulfate aqueous solution) at $60^{\circ} \mathrm{C}$ for $50 \mathrm{~s}$ to form patterned $\mathrm{Cu}$-network arrays. Then, the $\mathrm{Cu}$ network was spin-coated with a PDMS mixture and cured at $90^{\circ} \mathrm{C}$ for $30 \mathrm{~min}$ in a vacuum oven. The PDMS mixture was obtained by mixing an elastomer with a cross-linker at a mass ratio of 10:1, followed by ultrasonic treatment for 15 min to eliminate bubbles. The $\mathrm{Cu}$ network, covered with PDMS, was then wet-etched again in the etching liquid to create sufficient space between the PDMS and $\mathrm{Cu}$ network for friction and to provide space for the deposition of Ppy. Next, an inductively coupled plasma method was used to dry-etch the surface of the PDMS film with ICP-100A (Potentlube Technology Co., Ltd). Then, seven kinds of Ppy derivatives were deposited on the $\mathrm{Cu}$ network by electrochemical polymerization, forming seven independent gas-sensing units. The precursor solution contained $0.2 \mathrm{~mol} \mathrm{~L}^{-1}$ dopants and $0.1 \mathrm{~mol} \mathrm{~L}^{-1}$ pyrrole monomer. Sodium benzene sulfonate, sodium dodecyl benzene sulfonate, sodium dodecyl sulfate, oxalic acid, sodium oxalate, naphthalene sulfonic acid, and camphor sulfonic acid were used as the dopants. A Pt wafer, $\mathrm{Ag} / \mathrm{AgCl}$ electrode, and $\mathrm{Pt}$ wire served as the working, reference, and counter electrodes, respectively, during the electrochemical polymerizing process. Finally, a $\mathrm{Cu}$ film was deposited on the rear surface of the PDMS film by means of electron-beam evaporation, to act as the opposite electrode.

\section{Characterization and measurements}

For the tests, the flexible gas sensor was affixed to the inner wall of a vehicle tailpipe. All the sample gases were purchased from Shenyang Xindongji Chemical Gas Co., Ltd. The concentrations of the sample gases $\left(\mathrm{NO}, \mathrm{NH}_{3}\right.$, and $\mathrm{CO}$ ) were $1000 \mathrm{ppm}$. The flow of the target gas and air was provided by a gas mixing system (MTI, GSL-3F). The gas flow rate was measured by a gas flow meter, and held at $20.57 \mathrm{~m} \mathrm{~s}^{-1}$ unless mentioned otherwise. The output current of the device was measured by a low-noise current preamplifier (SR570, Stanford Research Systems). All the sensing measurements were conducted at room temperature $\left(26^{\circ} \mathrm{C}\right)$. The morphology and microstructure of the material were investigated using a scanning electron microscope (SEM; Hitachi S4800).

\section{RESULTS AND DISCUSSION}

The design of the self-powered gas sensor for automotive exhaust gas is shown in Fig. 1. The $\mathrm{NO}, \mathrm{NH}_{3}$, and $\mathrm{CO}$ in automotive exhaust gas can all affect the human respiratory system, eyes, and skin, as shown in Fig. 1a. As these kinds of gases cannot be detected by the human senses, there is a need for a means of rapidly detecting automotive exhaust gas in the atmosphere. Our new selfpowered automotive exhaust gas sensor is driven by the gas flow and generates triboelectric-sensing signals for the detection of toxic gases. The output current signals are immediately sent to a data-collecting system so that the 


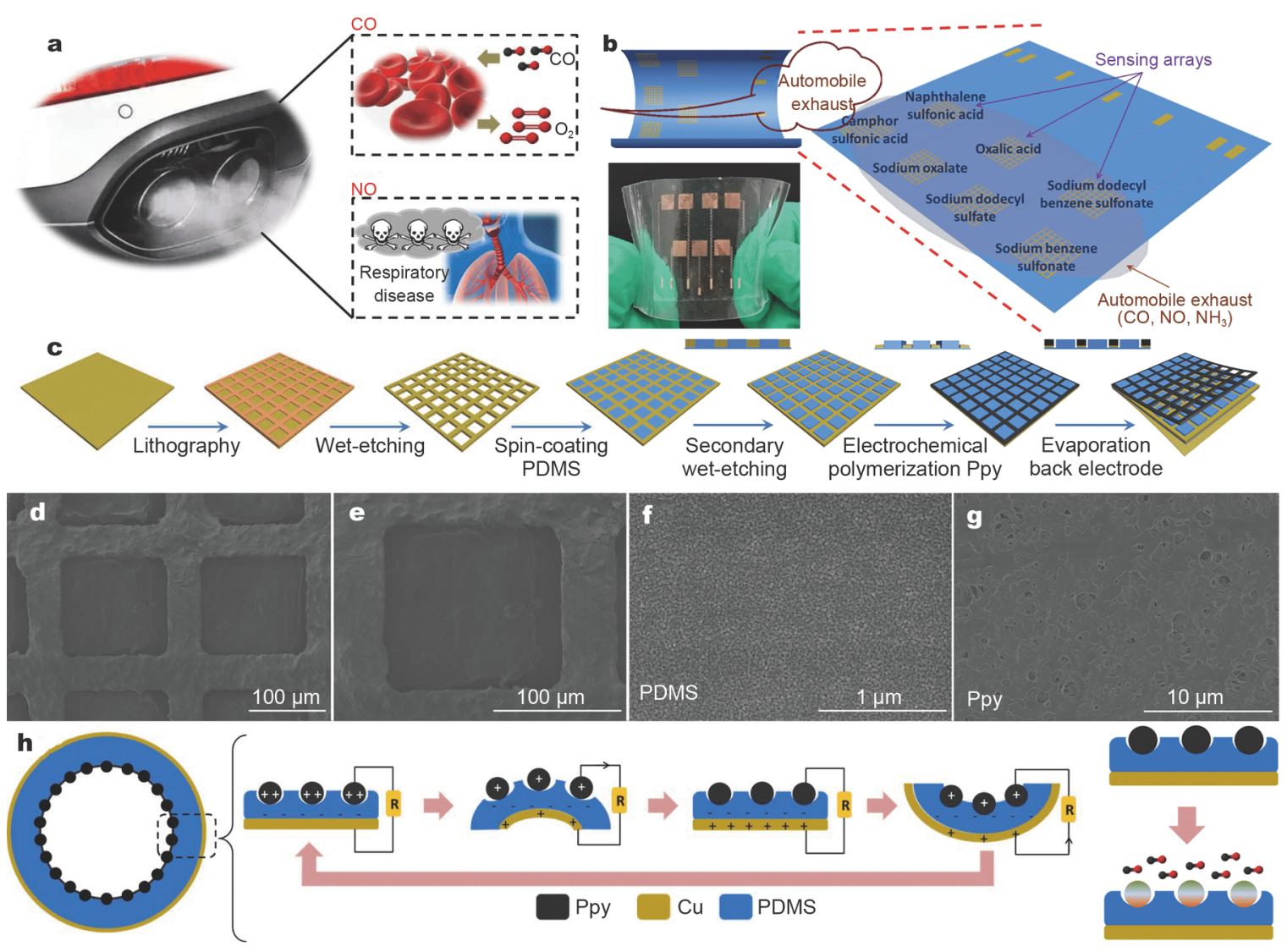

Figure 1 Experimental design of self-powered gas sensor. (a) Damage to human body caused by automotive exhaust gas. (b) Design of the gas sensor for exhaust gas analysis. Inset shows an image of the device. (c) Fabrication of gas sensor. SEM images of (d, e) a single gas-sensing unit, (f) PDMS and (g) Ppy-NSA. (h) Working mechanism.

automotive exhaust gases can be monitored in real time. Fig. $1 \mathrm{~b}$ shows the experimental design of the self-powered gas sensor for the real-time monitoring of automotive exhaust gas. The device is rolled up and installed in the automobile tailpipe. The device is itself pipe-shaped, such that it can easily be driven by the exhaust gas flow. When the exhaust gas passes over the device, current signals are generated by the sensing units due to the vibration of the device (triboelectrification). The multiplexed sensing unit arrays (different Ppy derivatives) output different current signals for specific gas species. The inset in Fig. $1 \mathrm{~b}$ shows how the device can bend, thus enabling real-time gas sensing in a vehicle tailpipe. To better demonstrate the flexibility, a device without a $\mathrm{Cu}$ back electrode is shown.

Fig. 1c shows the fabrication of the self-powered exhaust-gas sensor. The device mainly consists of three layers: Ppy on a $\mathrm{Cu}$ network, a PDMS layer, and a $\mathrm{Cu}$ back electrode. The Ppy nanostructures are deposited on the $\mathrm{Cu}$ network and act as the functional (sensing/triboelectrification) materials. The PDMS nanostructured layer acts as both the negative triboelectric material and the flexible substrate. The $\mathrm{Cu}$ film on the back of the PDMS layer acts as the other electrode. The size of the device is typically $5 \mathrm{~cm} \times 6 \mathrm{~cm}$, and each internal sensing unit (of which there are seven) is $0.5 \mathrm{~cm} \times 0.5 \mathrm{~cm}$. Here, seven different Ppy derivatives (doped with different dopants or surfactants) are synthesized independently on different sensing units. The sensing units are labeled PpySBS, Ppy-SDBS, Ppy-SDS, Ppy-OA, Ppy-SO, Ppy-NSA, and Ppy-CSA, depending on the dopants (sodium benzene sulfonate, sodium dodecyl benzene sulfonate, sodium dodecyl sulfate, oxalic acid, sodium oxalate, naphthalene sulfonic acid, and camphor sulfonic acid, respectively). SEM images of each sensing unit on the self-powered exhaust gas sensor are shown in Fig. 1d and e. The detailed structures are highly uniform. Fig. If shows the SEM image of the PDMS layer. The surface of the PDMS layer is treated using an inductively coupled plasma. Fig. 1g shows the morphology of the Ppy-NSA. The rough surfaces of the PDMS and Ppy increase the 
active surface area contributing to the contact/triboelectrification.

The working mechanism of the self-powered automotive exhaust sensor is schematically illustrated in Fig. $1 \mathrm{~h}$. The mechanism is based on the coupling between the triboelectric effect of the PDMS/Ppy nanostructures and gas-sensing ability of the Ppy [43-45]. There is a gap between the PDMS layer and Ppy on the $\mathrm{Cu}$ network. This provides sufficient space for friction between the PDMS layer and Ppy. The gap width changes when the sensor is applied with vibration caused by gas flow. Due to the difference in the electron affinities, surface charges are generated by a triboelectrification process when the Ppy comes into contact with the PDMS layer [46,47]. In the initial state, the Ppy is fully in contact with the PDMS, which induces the transfer of electrons from the Ppy to the PDMS through a triboelectrification effect $[48,49]$. As a result, positive charges accumulate on the surface of the Ppy, while negative charges accumulate on the surface of the PDMS. At this time, the triboelectric charges on the surfaces are stable and there is no movement of the electrons in the external circuit. When the sample gas flows over the device, it causes the device to vibrate, and the PDMS and Ppy separate, leading to an imbalance in the triboelectric charges. The negative charges on the PDMS surface will transfer to the Ppy surface through the external circuit. When the PDMS comes into contact with the Ppy again, the decrease in the interlayer distance allows the electrons to return from the Ppy to the PDMS electrode, thus creating a reverse current. The electrostatic induction generates output current signals until the PDMS and Ppy completely come into contact with each other again. Thus, the alternative current can be observed in the external circuit while the device is vibrating. The triboelectrification effect between the Ppy and PDMS is affected by the surface chemical/physical state of the frictional materials [34,47]. The changed Ppy chemical state will influence the surface charge carrier density of the Ppy, thus resulting in different output currents according to the gas atmosphere. In this case, the interaction between the gas molecules and Ppy is multiform [50-52]. For reducing gases like $\mathrm{NH}_{3}$, there is a reduction in the charge carrier density. Since the majority carrier (hole) density decreases due to the electron-donating nature of the $\mathrm{NH}_{3}$, it results in a decrease in the conductivity and an increase in the resistance. For an oxidizing gas like NO, there is an increase in the charge carrier concentration, since $\mathrm{NO}$ is electron-accepting in nature and increases the conductivity of the material, resulting in the decreased resistance of the Ppy and an increase in the output current.

Fig. 2 shows that the self-powered automotive exhaust gas sensor can be easily driven by the gas flow and convert mechanical energy into triboelectric current. Our experiments were conducted at room temperature $\left(26^{\circ} \mathrm{C}\right)$ and $40 \%$ relative humidity (RH). In Fig. $2 \mathrm{a}$, the output short-circuit current of the Ppy-NSA sensor unit is about $20 \mathrm{nA}$ when the gas flow velocity is $20.57 \mathrm{~m} \mathrm{~s}^{-1}$. Fig. $2 \mathrm{~b}$ shows that the output open-circuit voltage of the PpyNSA sensor unit is about $0.5 \mathrm{~V}$. The triboelectric current output from the sensor unit can be affected by the gas flow velocity, as shown in Fig. 2c. At gas flow velocities of $11.75,14.69,17.63$, and $20.57 \mathrm{~m} \mathrm{~s}^{-1}$, the output current of the Ppy-NSA sensing unit is $6.672,10.061,12.817$ and $19.994 \mathrm{nA}$, respectively. The relationship between the output current and the gas flow velocity is shown in Fig. 2 d. The current output by the sensor unit increases with the velocity of the gas flow. Fig. 2e shows the continuity and stability of the sensor unit. The output current signal remains at around $25 \mathrm{nA}$ for $2 \mathrm{~h}$. The exhaust gas sensor has good stability and repeatability, which would allow it to be applied to the continuous testing of a vehicle over an extended duration. The power density of the sensor unit is $40 \mathrm{nW} \mathrm{cm}$. The output of the unit can charge a $1-\mu \mathrm{F}$ capacitor to $0.49 \mathrm{~V}$ in $700 \mathrm{~s}$ (black curve in Fig. $2 \mathrm{f}$ ), a $10-\mu \mathrm{F}$ capacitor to $0.22 \mathrm{~V}$ in $700 \mathrm{~s}$ (red curve in Fig. 2f), and a $22-\mu \mathrm{F}$ capacitor to $0.14 \mathrm{~V}$ in $700 \mathrm{~s}$ (blue curve in Fig. 2f), such that it could power some small electronic devices or be applied to energy storage.

The triboelectric gas-sensing performance of individual sensing units was tested with different gases, as shown in Fig. 3. The experiment was conducted in a $20.57-\mathrm{m} \mathrm{s}^{-1}$ gas flow and at room temperature $\left(26^{\circ} \mathrm{C}\right)$. Fig. 3a shows the output current signal of the Ppy-OA sensing unit in $\mathrm{NH}_{3}$ gas flow of different concentrations. Upon setting the concentrations of the $\mathrm{NH}_{3}$ in the gas flows to $0,50,100$, 150,200 and $250 \mathrm{ppm}$, the triboelectric currents output by the sensing unit were $12.817,11.354,10.235,9.138$, 8.317 , and $6.959 \mathrm{nA}$, respectively. The output triboelectric current thus decreased with an increase in the $\mathrm{NH}_{3}$ concentration. As shown in Fig. 3b, there is an approximately linear relationship between the output current and the $\mathrm{NH}_{3}$ concentration. Fig. $3 \mathrm{~b}$ also shows the relationship between the response and the $\mathrm{NH}_{3}$ concentration. The response $(R \%)$ of a Ppy-OA sensing unit to $\mathrm{NH}_{3}$ can be roughly defined as:

$R \%=\frac{I_{\mathrm{am}}-I_{\mathrm{a}}}{I_{\mathrm{a}}} \times 100 \%$,

where $I_{\mathrm{a}}$ and $I_{\mathrm{am}}$ represent the maximum output currents 

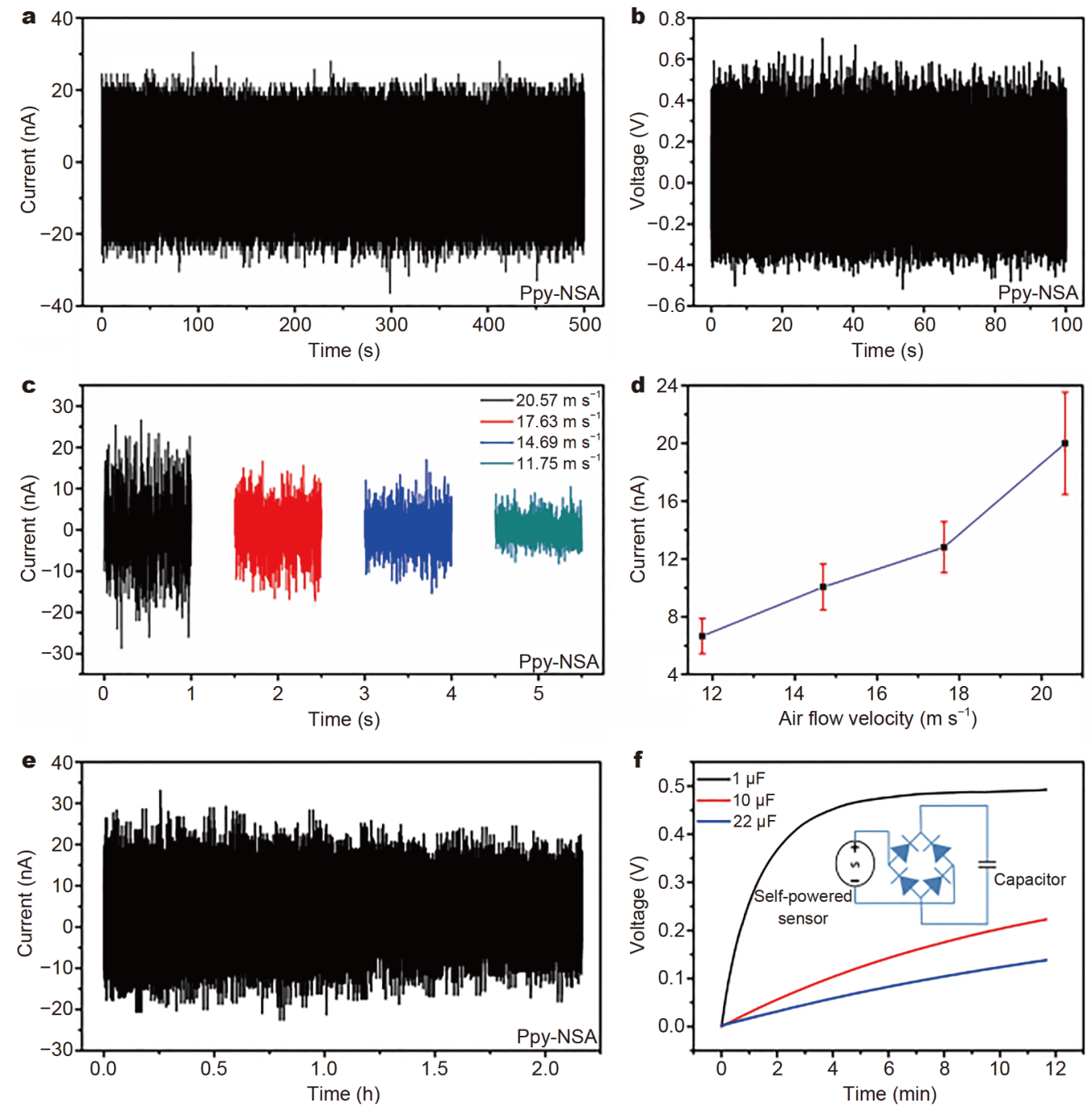

Figure 2 Triboelectric output performance of Ppy-NSA sensing unit. (a) Output current signal of unit under a constant gas flow. (b) Output voltage signal of the sensor. (c) Output current of the device under different gas flow velocities. (d) Relationship between gas flow velocity and output current signal. (e) Long-term stability of sensor. (f) Charging curves for 1-, 10-, and $22-\mu \mathrm{F}$ capacitors when being charged by the unit. The inset shows the circuit diagram.

in the period for air and different concentrations of $\mathrm{NH}_{3}$ gas, respectively. For $\mathrm{NH}_{3}$ concentrations of 50, 100, 150, 200 and $250 \mathrm{ppm}$, the response was $-11.42 \%,-20.15 \%$, $-28.71 \%,-35.11 \%$, and $-45.70 \%$, respectively. In addition, the Ppy-OA sensing unit is also highly sensitive to $\mathrm{NO}$ gas flows, as shown in Fig. $3 \mathrm{c}$ and d. For NO gas flows of $0,50,100,150,200$, and $250 \mathrm{ppm}$, the current output by the sensing unit is $9.650,10.362,11.113,12.346$, 13.446 , and $14.667 \mathrm{nA}$, respectively, while the corresponding responses are $7.38 \%, 15.15 \%, 27.94 \%, 39.33 \%$, and $51.98 \%$. The triboelectric gas-sensing performance of Ppy-CSA sensing unit is shown in Fig. 3e-h. For $\mathrm{NH}_{3}$ gas flows of $0,50,100,150,200$, and $250 \mathrm{ppm}$, the tribo- electric current output from the sensing unit is 28.275 , $26.629,23.550,17.725,17.000$, and $15.839 \mathrm{nA}$, respectively, while the corresponding response is $-5.82 \%$, $-16.71 \%,-37.31 \%,-39.88 \%$, and $-43.98 \%$. For NO gas flows of $0,50,100,150,200$, and $250 \mathrm{ppm}$, the shortcircuit current of the sensing unit is 29.916, 47.228, $65.966,74.008,91.804$, and $114.569 \mathrm{nA}$, respectively, while the corresponding response is $57.87 \%, 120.51 \%$, $147.39 \%, 206.88 \%$, and $282.98 \%$. These excellent responses show that the self-powered gas sensor could be applied to the monitoring of automotive exhaust gas.

The sensing units doped with different dopants/surfactants have different selectivities for the detection of 

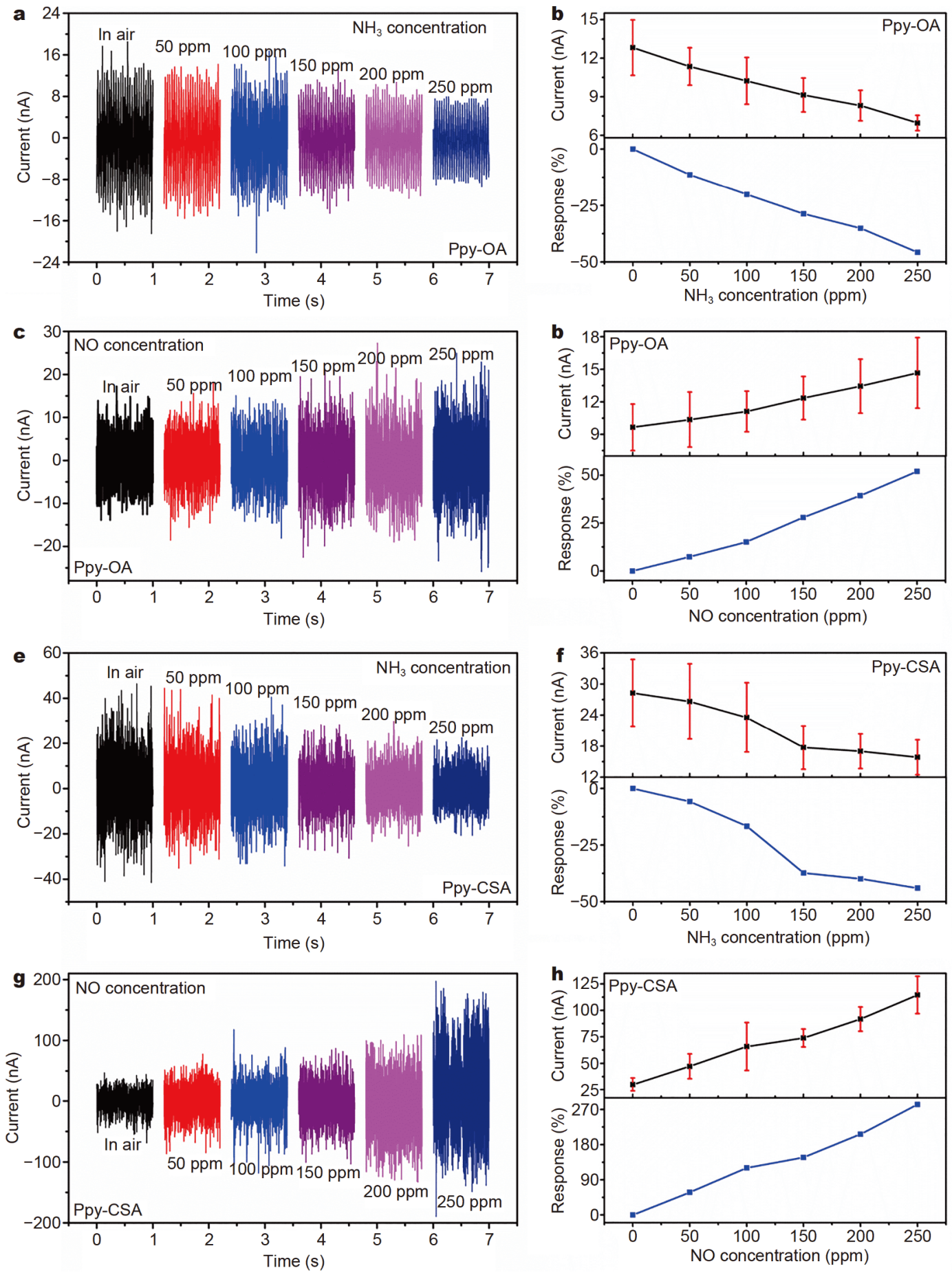

Figure 3 Triboelectric-gas-sensing performance of two sensing units. (a-d) Sensing performance of Ppy-OA sensing unit in $\mathrm{NH}_{3}$ and $\mathrm{NO}_{\text {gas }}$ flows. (e-h) Sensing performance of Ppy-CSA sensing unit in $\mathrm{NH}_{3}$ and $\mathrm{NO}$ gas flows.

specific gases. Therefore, the sensing units can distinguish chemically diverse gases at the same time and analyze the various chemical components of automotive exhaust. Here, seven sensing units (Ppy-SDBS, Ppy-SDS, Ppy-
SBS, Ppy-OA, Ppy-SO, Ppy-NSA, and Ppy-CSA) are designed to output current signals for three target gases (CO, NO, and $\mathrm{NH}_{3}$ ), as shown in Fig. 4. The responses of the seven sensing units are $-11.70 \%,-5.16 \%,-22.02 \%$, 

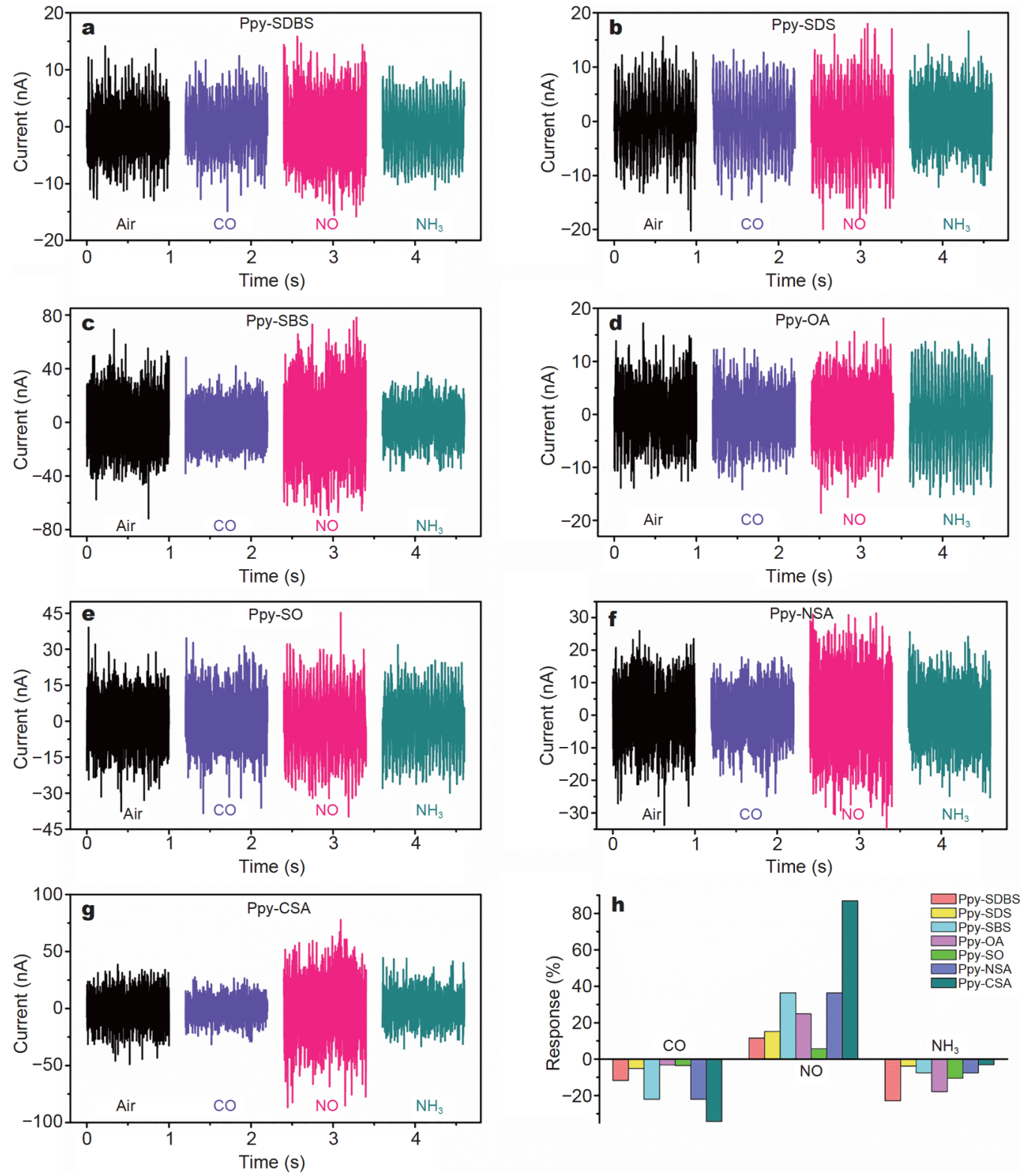

Figure 4 Triboelectric-gas-sensing performance of seven sensing units in different gases. (a-g) Output currents from seven sensing units in 50-ppm $\mathrm{CO}, 50-\mathrm{ppm} \mathrm{NO}$, and 50-ppm $\mathrm{NH}_{3}$ gas flows, respectively. (h) Responses of seven sensing units.

$-3.15 \%,-3.53 \%,-22.02 \%$, and $-34.23 \%$, respectively, for a 50 -ppm CO gas flow. For a 50-ppm NO gas flow, the responses are $11.55 \%, 15.19 \%, 36.42 \%, 24.84 \%, 5.64 \%$, $36.42 \%$, and $86.91 \%$, respectively. For a $50-\mathrm{ppm} \mathrm{NH}_{3}$ gas flow, the responses are $-22.87 \%,-3.84 \%,-7.55 \%$, $-17.90 \%,-10.49 \%,-7.55 \%$, and $-3.12 \%$, respectively. These results point to the potential of the self-powered gas sensor for the monitoring of automotive exhaust gas.

Fig. 5 shows the real-time continuous sensing profiles of the sensing units against specific gases (response/re- covery processes). The response times of Ppy-CSA for CO, Ppy-SBS for NO, and Ppy-NSA for $\mathrm{NH}_{3}$ are about 11,31 , and $13 \mathrm{~s}$, while the recovery times are about 5,30 , and $12 \mathrm{~s}$, respectively. These results indicate that the device offers an effective means of monitoring automotive exhaust gas in real time. The response of the device (PpyNSA sensing unit) for $\mathrm{CO}$ at different gas flow velocities is shown in Fig. 6. In Fig. 6a, when the gas flow rate is $20.57,17.63,14.69$ and $11.75 \mathrm{~m} \mathrm{~s}^{-1}$, the output current is 19.99, 12.82, 10.06 and $6.67 \mathrm{nA}$ for air, and 14.83, 9.84, 

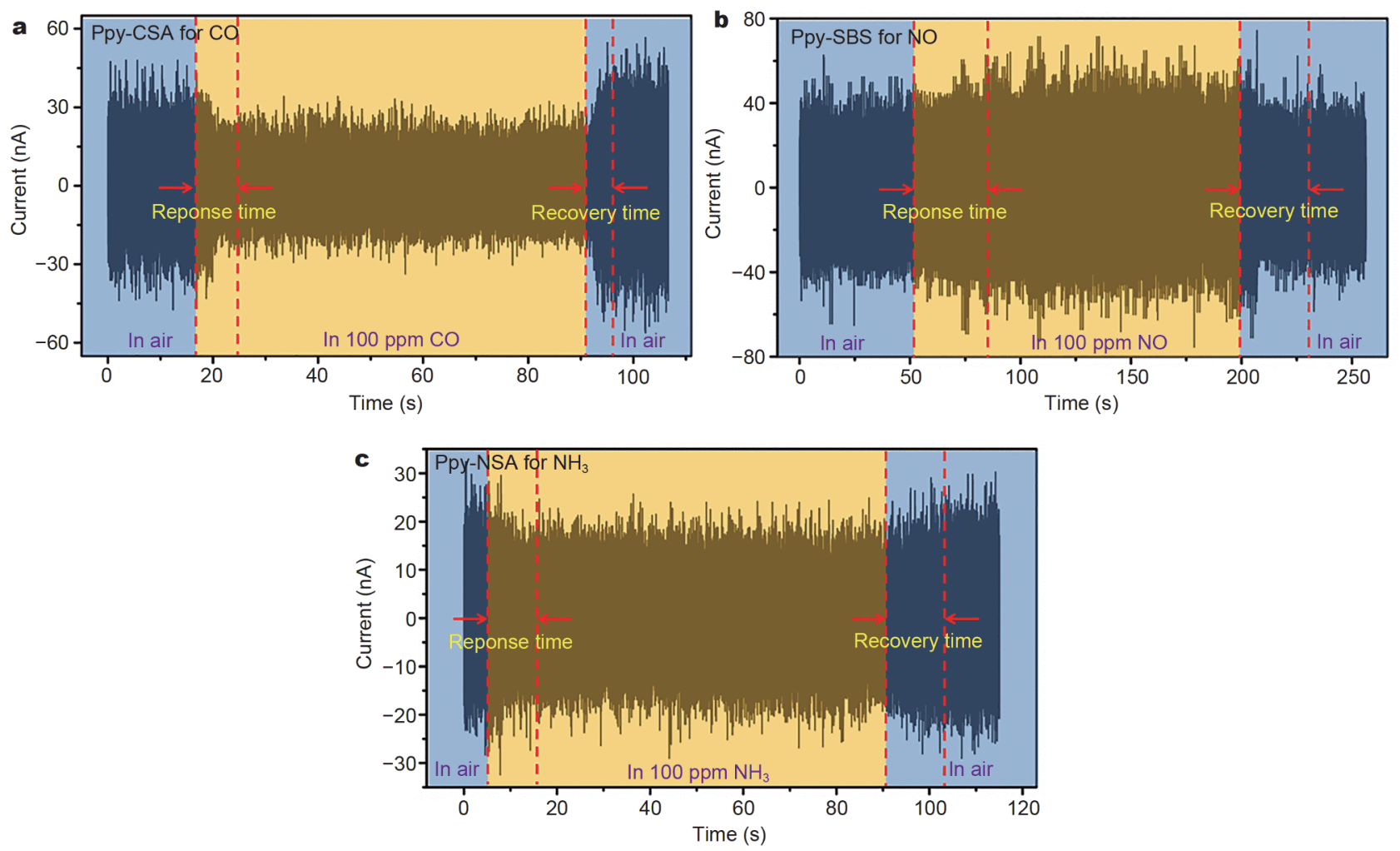

Figure 5 Response/recovery processes of different sensing units. (a) Ppy-CSA sensing unit for CO. (b) Ppy-SBS sensing unit for NO. (c) Ppy-NSA sensing unit for $\mathrm{NH}_{3}$.
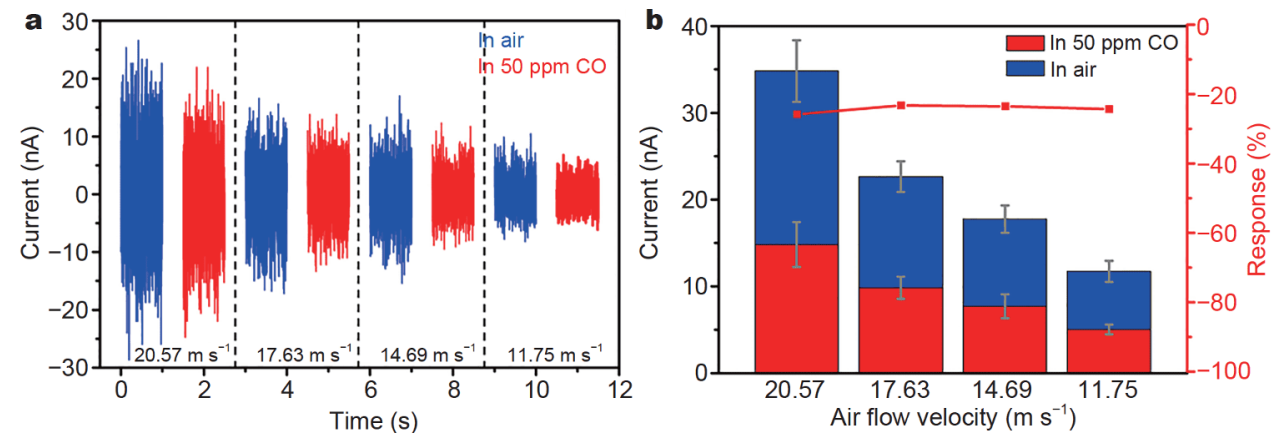

Figure 6 Sensing performance of Ppy-NSA sensing unit under different gas flow velocities. (a) Output current under different gas flow velocities for 50-ppm CO and in air. (b) Response of Ppy-NSA sensing unit under different gas flow velocities.

7.70 and $5.05 \mathrm{nA}$ for a $50-\mathrm{ppm} \mathrm{CO}$ gas flow, respectively. The device response for different gas flow rates is almost the same, as shown in Fig. $6 \mathrm{~b}$ (the response is $-25.83 \%$, $-23.26 \%,-23.50 \%$, and $-24.33 \%)$. The results show that the sensing performance of the device is highly stable for different gas flow velocities, confirming a wide range of operating conditions.

In practical gas-monitoring applications, the effect of $\mathrm{RH}$ on the gas response of the device is very important.
Fig. 7 shows the influence of the $\mathrm{RH}$ on the $\mathrm{NH}_{3}$ response of the Ppy-CSA sensing unit. The output current signals of the Ppy-CSA sensing unit under air flow and 50-ppm $\mathrm{NH}_{3}$ under different $\mathrm{RH}$ conditions $(40 \%, 60 \%, 80 \%$, and $100 \%$ RH) are shown in Fig. 7a. Fig. 7b shows that the output current decreases as the $\mathrm{RH}$ increases both in air and $\mathrm{NH}_{3}$. When the PDMS and Ppy come into contact and then separate, electrons transfer from Ppy to PDMS at the interface. As the humidity gradually increases, the 
surface of the Ppy will adsorb water molecules, leading to weak triboelectric effect and a reduction in the charge transfer [53-55]. As shown in Fig. 7c, the $\mathrm{NH}_{3}$ response increases with the humidity, even at high humidity levels. These results point to the potential for applying the unit to gas flows with a high humidity.

The present study devised a self-powered gas sensor for the real-time monitoring of automotive exhaust gas without an external electricity source, as shown in Fig. 8. A schematic diagram of the device is shown in Fig. 8a. The automotive exhaust gas is collected by a gas-mixing system, which can change the gas atmosphere (pure air and real automotive exhaust gas). The gas sensor can monitor the changes in the automotive exhaust gas in real time, and output current signals without an external power source. The current signals are sent to a data collector/computer which analyzes the exhaust gas. The automotive exhaust gases from two different vehicles (a sports utility vehicle (Fig. 8b, c) and a sedan ((Fig. 8d, e)) were tested using the gas sensor under a gas flow velocity of $20.57 \mathrm{~m} \mathrm{~s}^{-1}$ (the gas flow velocity was maintained by the gas-mixing system). The output current from the
Ppy-NSA sensing unit for pure air was measured first. When the air was switched to the exhaust gas from the sports utility vehicle, the output current decreased from $\sim 25$ to $\sim 20 \mathrm{nA}$ in $\sim 40 \mathrm{~s}$, as shown in Fig. 8c. When the air was switched to the exhaust gas from the sedan, the output current increased from $\sim 25$ to $\sim 40 \mathrm{nA}$ in $\sim 150 \mathrm{~s}$, as shown in Fig. 8e. These results imply that the concentrations of exhaust gas from the two kinds of vehicles are totally different. The competition mechanism which is available for the gas-sensing performance is expressed in the output current signals. The rising and falling current signals indicate that the exhaust gas from the sports utility vehicle contains more $\mathrm{CO}$ and $\mathrm{NH}_{3}$ than $\mathrm{NO}$, while the exhaust gas from the sedan contains more NO than $\mathrm{CO}$ and $\mathrm{NH}_{3}$. These different gas-monitoring results demonstrate that the device could be applied to real-time automotive exhaust gas monitoring without any external power.

\section{CONCLUSIONS}

A self-powered gas sensor was developed for the real-time monitoring of automotive exhaust gas. The device can be
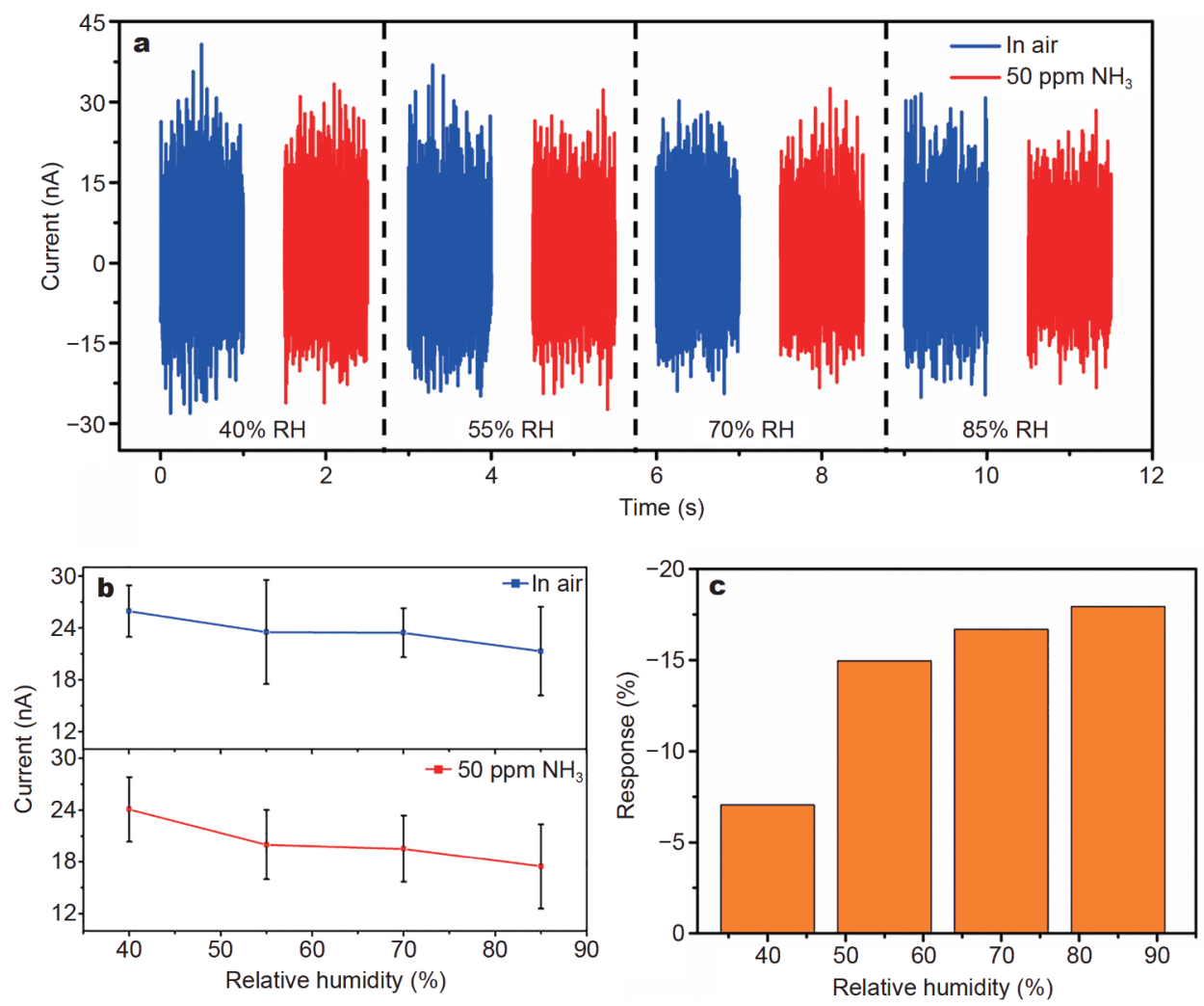

Figure 7 Sensing performance of Ppy-CSA sensing unit under different gas flow velocities. (a) Output current from the Ppy-CSA sensing unit for air and $50-\mathrm{ppm} \mathrm{NH}_{3}$ gas flows under different conditions $(40 \%, 55 \%, 70 \%$, and $85 \% \mathrm{RH})$. (b) Relationship between output current and $\mathrm{RH}$ for air and 50-ppm $\mathrm{NH}_{3}$ gas flow. (c) Relationship between response and $\mathrm{RH}$. 

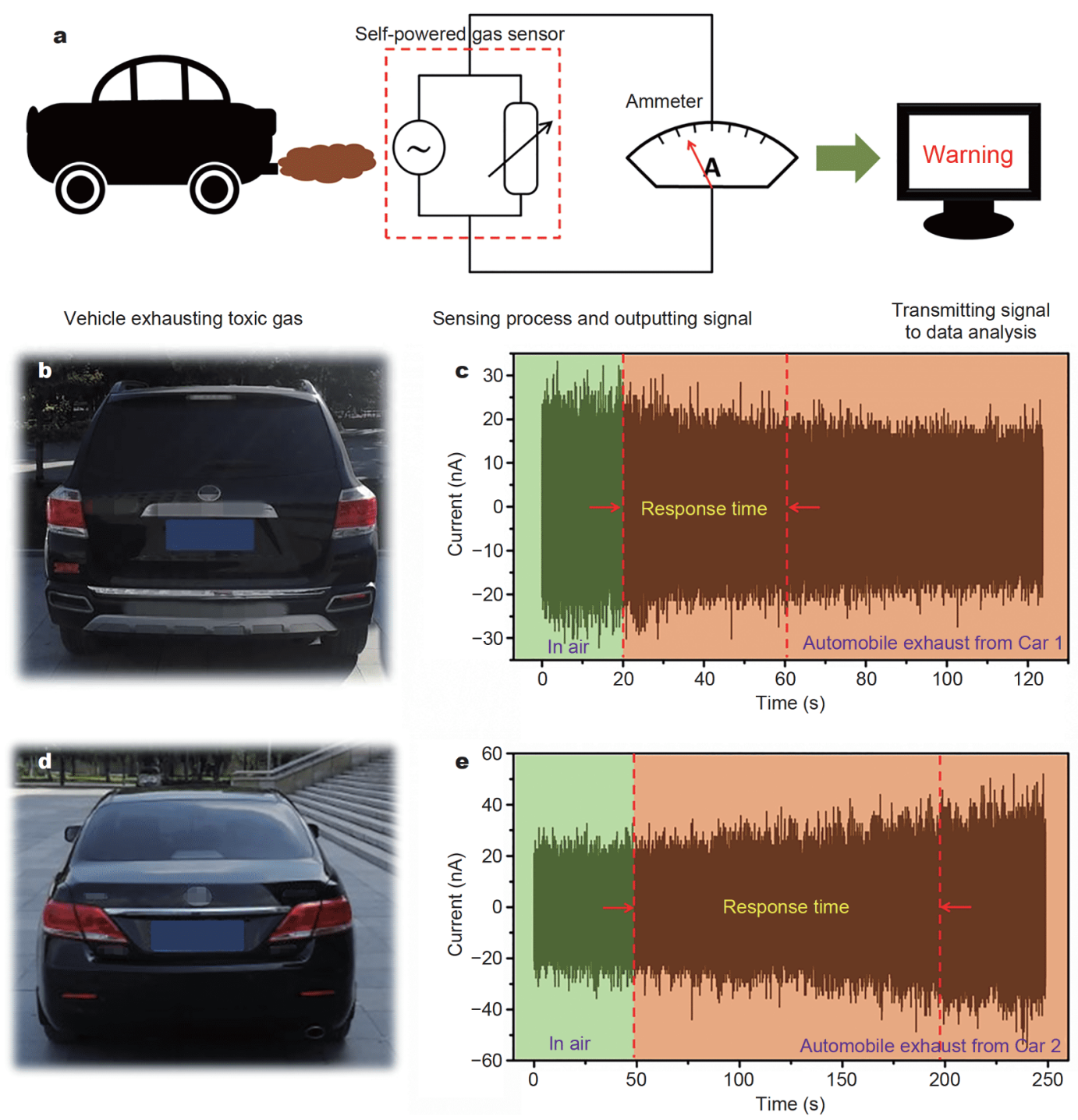

Figure 8 Practical application of self-powered automotive exhaust gas sensor. (a) Schematic diagrams of self-powered automotive exhaust gas sensor. (b, d) Vehicles used for the tests. (c, e) Current signals output by the device for automotive exhaust gases.

driven by the gas flow, while the output triboelectric current signals provide sensing data without the need for any external power supply. The mechanism is based on the triboelectric/gas-sensing coupling effect between Ppy derivatives and PDMS. The application of the device to the analysis of automotive exhaust gas was demonstrated using two actual vehicles. This new device should promote the development of self-powered automotive exhaust gas monitoring systems and could be applied to intelligent vehicles in the future.

Received 17 April 2019; accepted 27 May 2019; published online 21 June 2019
1 Wales DJ, Grand J, Ting VP, et al. Gas sensing using porous materials for automotive applications. Chem Soc Rev, 2015, 44: 4290-4321

2 Twigg MV. Progress and future challenges in controlling automotive exhaust gas emissions. Appl Catal B-Environ, 2007, 70: 215

3 Fleming WJ. New automotive sensors-a review. IEEE Senss J, 2008, 8: 1900-1921

4 Liu X, Cheng S, Liu H, et al. A survey on gas sensing technology. Sensors, 2012, 12: 9635-9665

5 Fang X, Zong B, Mao S. Metal-organic framework-based sensors for environmental contaminant sensing. Nano-Micro Lett, 2018, 10: 64

6 Wang T, Huang D, Yang Z, et al. A review on graphene-based gas/ 
vapor sensors with unique properties and potential applications. Nano-Micro Lett, 2016, 8: 95-119

7 Zhong T, Guan H, Dai Y, et al. A self-powered flexibly-arranged gas monitoring system with evaporating rainwater as fuel for building atmosphere big data. Nano Energy, 2019, 60: 52-60

$8 \mathrm{Fu} \mathrm{Y}, \mathrm{He} \mathrm{H}$, Liu Y, et al. Self-powered, stretchable, fiber-based electronic-skin for actively detecting human motion and environmental atmosphere based on a triboelectrification/gas-sensing coupling effect. J Mater Chem C, 2017, 5: 1231-1239

9 Zhang D, Liu J, Jiang C, et al. Quantitative detection of formaldehyde and ammonia gas via metal oxide-modified graphenebased sensor array combining with neural network model. Sensor Actuat B-Chem, 2017, 240: 55-65

$10 \mathrm{He} \mathrm{H}$, Dong C, Fu Y, et al. Self-powered smelling electronic-skin based on the piezo-gas-sensor matrix for real-time monitoring the mining environment. Sensor Actuat B-Chem, 2018, 267: 392-402

11 Liang Q, Li D, Gao S, et al. Room-temperature $\mathrm{NH}_{3}$ sensors with high sensitivity and short response/recovery times. Chin Sci Bull, 2014, 59: 447-451

12 Liu DP, Chu YL, Wu XH, et al. Side-chain effect of organic semiconductors in OFET-based chemical sensors. Sci China Mater, 2017, 60: 977-984

13 Timmer B, Olthuis W, Berg A. Ammonia sensors and their applications-a review. Sensor Actuat B-Chem, 2005, 107: 666-677

14 Afzal A, Cioffi N, Sabbatini L, et al. $\mathrm{NO}_{x}$ sensors based on semiconducting metal oxide nanostructures: progress and perspectives. Sensor Actuat B-Chem, 2012, 171-172: 25-42

15 Li S, Wang M, Li C, et al. $\mathrm{Cu}_{x} \mathrm{O}$ self-assembled mesoporous microspheres with effective surface oxygen vacancy and their room temperature $\mathrm{NO}_{2}$ gas sensing performance. Sci China Mater, 2018, 61: 1085-1094

16 Xue X, Deng P, Yuan S, et al. CuO/PVDF nanocomposite anode for a piezo-driven self-charging lithium battery. Energy Environ Sci, 2013, 6: 2615-2620

17 Guan $\mathrm{H}$, Zhong $\mathrm{T}, \mathrm{He} \mathrm{H}$, et al. A self-powered wearable sweatevaporation-biosensing analyzer for building sports big data. Nano Energy, 2019, 59: 754-761

18 Duan J, Liang X, Guo J, et al. Ultra-stretchable and force-sensitive hydrogels reinforced with chitosan microspheres embedded in polymer networks. Adv Mater, 2016, 28: 8037-8044

$19 \mathrm{He} \mathrm{H,} \mathrm{Fu} \mathrm{Y,} \mathrm{Zhao} \mathrm{T,} \mathrm{et} \mathrm{al.} \mathrm{All-solid-state} \mathrm{flexible} \mathrm{self-charging}$ power cell basing on piezo-electrolyte for harvesting/storing bodymotion energy and powering wearable electronics. Nano Energy, 2017, 39: 590-600

20 Huang $\mathrm{Y}$, Zhu M, Huang Y, et al. Multifunctional energy storage and conversion devices. Adv Mater, 2016, 28: 8344-8364

21 Zhao K, Wang Y, Han L, et al. Nanogenerator-based self-charging energy storage devices. Nano-Micro Lett, 2019, 11: 19

22 Shao $\mathrm{H}$, Cheng $\mathrm{P}$, Chen $\mathrm{R}$, et al. Triboelectric-electromagnetic hybrid generator for harvesting blue energy. Nano-Micro Lett, 2018, 10: 54

23 Wang $\mathrm{K}$, Zhang X, Sun X, et al. Conducting polymer hydrogel materials for high-performance flexible solid-state supercapacitors. Sci China Mater, 2016, 59: 412-420

24 Zhang X, Zhang H, Lin Z, et al. Recent advances and challenges of stretchable supercapacitors based on carbon materials. Sci China Mater, 2016, 59: 475-494

25 Uddin ASMI, Kumar PS, Hassan K, et al. Enhanced sensing performance of bimetallic $\mathrm{Al} / \mathrm{Ag}$-CNF network and porous PDMSbased triboelectric acetylene gas sensors in a high humidity at- mosphere. Sensor Actuat B-Chem, 2018, 258: 857-869

26 Uddin ASMI, Chung GS. A self-powered active hydrogen sensor based on a high-performance triboelectric nanogenerator using a wrinkle-micropatterned PDMS film. RSC Adv, 2016, 6: 6303063036

27 Lin ZH, Zhu G, Zhou YS, et al. A self-powered triboelectric nanosensor for mercury ion detection. Angew Chem Int Ed, 2013, 52: 5065-5069

28 Uddin ASMI, Yaqoob U, Chung GS. Improving the working efficiency of a triboelectric nanogenerator by the semimetallic PEDOT:PSS hole transport layer and its application in self-powered active acetylene gas sensing. ACS Appl Mater Interfaces, 2016, 8: 30079-30089

29 Wen Z, Chen J, Yeh MH, et al. Blow-driven triboelectric nanogenerator as an active alcohol breath analyzer. Nano Energy, 2015, 16: $38-46$

30 Wang Q, Jian M, Wang C, et al. Carbonized silk nanofiber membrane for transparent and sensitive electronic skin. Adv Funct Mater, 2017, 27: 1605657

31 Fu Y, He H, Zhao T, et al. A self-powered breath analyzer based on PANI/PVDF piezo-gas-sensing arrays for potential diagnostics application. Nano-Micro Lett, 2018, 10: 76

32 Yang $\mathrm{Y}$, Zhang $\mathrm{H}$, Chen J, et al. Single-electrode-based sliding triboelectric nanogenerator for self-powered displacement vector sensor system. ACS Nano, 2013, 7: 7342-7351

33 Kanfer G, Courthéoux T, Peterka M, et al. Mitotic redistribution of the mitochondrial network by Miro and Cenp-F. Nat Commun, 2015, 6: 8015

34 Xue X, Fu Y, Wang Q, et al. Outputting olfactory bionic electric impulse by PANI/PTFE/PANI sandwich nanostructures and their application as flexible, smelling electronic skin. Adv Funct Mater, 2016, 26: 3128-3138

35 Fu Y, Zhang M, Dai Y, et al. A self-powered brain multi-perception receptor for sensory-substitution application. Nano Energy, 2018, 44: $43-52$

36 Zhang W, Zhang L, Gao H, et al. Self-powered implantable skinlike glucometer for real-time detection of blood glucose level in vivo. Nano-Micro Lett, 2018, 10: 32

37 Dai $\mathrm{Y}, \mathrm{Fu} \mathrm{Y}$, Zeng $\mathrm{H}$, et al. A self-powered brain-linked vision electronic-skin based on triboelectric-photodetecing pixeladdressable matrix for visual-image recognition and behavior intervention. Adv Funct Mater, 2018, 28: 1800275

38 Han W, Zhang L, He H, et al. Self-powered vision electronic-skin basing on piezo-photodetecting Ppy/PVDF pixel-patterned matrix for mimicking vision. Nanotechnology, 2018, 29: 255501

39 Bose S, Kuila T, Uddin ME, et al. In-situ synthesis and characterization of electrically conductive polypyrrole/graphene nanocomposites. Polymer, 2010, 51: 5921-5928

40 Wan S, Guo J, Kim J, et al. A photoconductive covalent organic framework: Self-condensed arene cubes composed of eclipsed 2D polypyrene sheets for photocurrent generation. Angew Chem Int Ed, 2009, 48: 5439-5442

$41 \mathrm{Du} \mathrm{Y}$, Shen SZ, Cai K, et al. Research progress on polymerinorganic thermoelectric nanocomposite materials. Prog Polymer Sci, 2012, 37: 820-841

42 Zhang L, Du W, Nautiyal A, et al. Recent progress on nanostructured conducting polymers and composites: synthesis, application and future aspects. Sci China Mater, 2018, 61: 303-352

43 Niu S, Wang S, Lin L, et al. Theoretical study of contact-mode triboelectric nanogenerators as an effective power source. Energy 
Environ Sci, 2013, 6: 3576-3583

$44 \mathrm{He} \mathrm{H}$, Zeng H, Fu Y, et al. A self-powered electronic-skin for realtime perspiration analysis and application in motion state monitoring. J Mater Chem C, 2018, 6: 9624-9630

45 Wen Z, Shen Q, Sun X. Nanogenerators for self-powered gas sensing. Nano-Micro Lett, 2017, 9: 45

46 Khan U, Kim SW. Triboelectric nanogenerators for blue energy harvesting. ACS Nano, 2016, 10: 6429-6432

47 Zeng $\mathrm{H}, \mathrm{He} \mathrm{H}, \mathrm{Fu} \mathrm{Y}$, et al. A self-powered brain-linked biosensing electronic-skin for actively tasting beverage and its potential application in artificial gustation. Nanoscale, 2018, 10: 19987-19994

48 Liu Y, Niu S, Wang ZL. Theory of tribotronics. Adv Electron Mater, 2015, 1: 1500124

49 Niu S, Liu Y, Chen X, et al. Theory of freestanding triboelectriclayer-based nanogenerators. Nano Energy, 2015, 12: 760-774

50 Bai H, Shi G. Gas sensors based on conducting polymers. Sensors, 2007, 7: 267-307

51 An $\mathrm{K}$, Jeong $\mathrm{S}$, Hwang $\mathrm{H}$, et al. Enhanced sensitivity of a gas sensor incorporating single-walled carbon nanotube-polypyrrole nanocomposites. Adv Mater, 2004, 16: 1005-1009

52 Ameer Q, Adeloju SB. Polypyrrole-based electronic noses for environmental and industrial analysis. Sensor Actuat B-Chem, 2005, 106: $541-552$

53 Lu CX, Han CB, Gu GQ, et al. Temperature effect on performance of triboelectric nanogenerator. Adv Eng Mater, 2017, 19: 1700275

54 Chang TH, Peng YW, Chen $\mathrm{CH}$, et al. Protein-based contact electrification and its uses for mechanical energy harvesting and humidity detecting. Nano Energy, 2016, 21: 238-246

55 Wei G, Bi Y, Li X, et al. Self-powered hybrid flexible nanogenerator and its application in bionic micro aerial vehicles. Nano Energy, 2018, 54: 10-16

Acknowledgements This work was supported by the National Natural Science Foundation of China (11674048), the Fundamental Research Funds for the Central Universities (N170505001 and N160502002) and the Program for Shenyang Youth Science and Technology Innovation Talents (RC170269).

Author contributions Xue X and Xing L devised the concept. Xue X and $\mathrm{He} \mathrm{H}$ designed the experiments. $\mathrm{He} \mathrm{H}$ and Zhang $\mathrm{M}$ performed the experiments. Xue X, He H, and Xing L analyzed the data. Zhao T, Zeng $\mathrm{H}$ and $\mathrm{He} \mathrm{H}$ characterized the materials. Xue $\mathrm{X}, \mathrm{He} \mathrm{H}$, and Xing L wrote the manuscript. All authors contributed to the general discussion.

Conflict of interest The authors declare that they have no conflicts of interest.

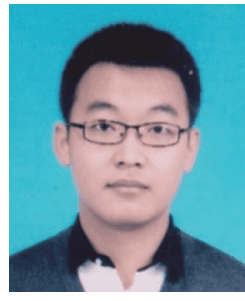

Haoxuan $\mathrm{He}$ is currently studying for the doctoral degree in the College of Sciences, Northeastern University, China. Now his research interests focus on the self-powered sensor, selfpowered electronic skin and self-charging power unit system.

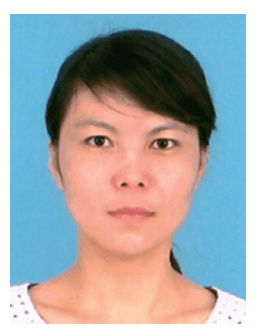

Lili Xing is a Professor at the University of Electronic Science and Technology of China. Her research mainly focuses on the synthesis of metal oxide nanostructures.

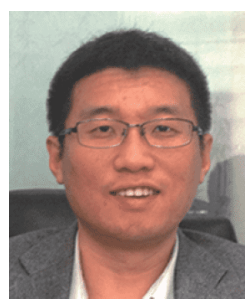

Xinyu Xue is a Professor at the University of Electronic Science and Technology of China and College of Sciences, Northeastern University, China. Currently he is working on the next generation of sensors and batteries, such as selfpowered active sensors and self-charging lithium battery.

\section{基于PDMS/Ppy摩擦气体传感阵列的自供电式气 体传感器用于室温实时监控尾气}

何吴轩 ${ }^{1,2}$, 张梦洋 ${ }^{2}$, 赵天铭 ${ }^{1,2}$, 曾辉 ${ }^{2}$, 邢丽丽 ${ }^{1,2^{*}}$, 薛欣宇 ${ }^{1,2^{*}}$

摘要 本文提出了一种用于汽车尾气实时监测的新型自供电式气 体传感器. 这种管形器件由聚二甲基硅氧烷/聚吡咯(PDMS/Ppy)摩 擦-气体传感单元阵列组成. 摩擦-气体传感单元可以直接将气流的 机械能转换为电能并输出摩擦电流. 输出电流的信号强度取决于 气流中目标化学气体 $\left(\mathrm{CO} 、 \mathrm{NH}_{3} 、 \mathrm{NO}\right)$ 的种类和浓度, 因此这种输 出电流可以同时作为传感信号. 这种自供电气体传感器将纳米发 电机和气体传感器集成于单一器件, 在一个物理过程中同时实现 摩擦发电和气体传感, 进而实现了自供电式气体传感器. 该装置可 固定在汽车排气管处, 无需外接电源即可对废气进行实时分析. 这 一工作为汽车尾气监测系统的发展开辟了新的研究方向, 将在大 气污染的检测方面起到重要作用. 